\title{
Reinstatement of Morphine-Conditioned Reward is Blocked by Memantine
}

\author{
Piotr Popik*,', Malgorzata Wrobel' and Adam Bisaga ${ }^{2}$ \\ 'Institute of Pharmacology, Polish Academy of Sciences, Kraków, Poland; ${ }^{2}$ New York State Psychiatric Institute at Columbia University, New York, \\ NY, USA
}

\begin{abstract}
Protection of abstinent individuals from relapse is the main goal of drug dependence treatment. Relapse is frequently precipitated by exposure to small doses of the drug of abuse or exposure to the environment that was previously associated with the drug. Mice exposed to morphine $(10 \mathrm{mg} / \mathrm{kg})$ in a unique test-box environment display a conditioned place preference for this environment. Such preference can be extinguished by subsequent pairing of physiological saline administration with the same environment. Once extinguished, the original place preference can be reinstated after a priming dose $(1-2.5 \mathrm{mg} / \mathrm{kg})$ of morphine is given. However, mice treated with 7.5 (but not 3.75) $\mathrm{mg} / \mathrm{kg}$ of memantine (the glutamate/NMDA receptor antagonist) during the extinction phase were insensitive to morphine's ability to reinstate the place preference 2 days after extinction conditionings. Effect of memantine was also observed when priming dose of morphine was given 21 days after extinction conditionings. In contrast, morphine's ability to reinstate conditioned response was not affected by treatment with $10 \mathrm{mg} / \mathrm{kg}$ of chlordiazepoxide, $0.5 \mathrm{mg} / \mathrm{kg}$ of LSD-25, or I mg/kg of morphine given during extinction conditionings. A separate experiment demonstrated that memantine $(7.5 \mathrm{mg} / \mathrm{kg})$ treatment did not affect learning. We show for the first time that memantine treatment during extinction conditionings may abolish the ability of drug-related cues to evoke reinstatement, suggesting that this NMDA receptor antagonist can be useful in preventing relapse in opioid dependent individuals. Neuropsychopharmacology (2006) 31, I60-170. doi: I0.1038/sj.npp. I300760; published online I I May 2005
\end{abstract}

Keywords: NMDA receptor antagonist; opiate; reward; reinstatement; conditioned place preference

\section{INTRODUCTION}

Drug dependence is a chronic, relapsing disorder (Leshner, 1997) and treatment efforts often focus on the prevention of relapse in abstinent individuals (McLellan et al, 2000). Exposure to environmental cues, like drug paraphernalia or places of drug consumption, as well as re-experience of drug effects, can elicit drug craving and seeking and trigger relapse in abstinent individuals (O'Brien et al, 1998; Shalev et al, 2002). Therefore, pharmacological treatments that would protect abstinent individuals from relapse should focus on diminishing reactivity to drug-related pharmacological and environmental stimuli, thus reducing drug craving and preventing relapse. Relapse-prevention pharmacotherapy might offer a breakthrough in the treatment of addictions, and animal models of drug relapse could be used to screen for such medication (el Guebaly and Hodgins, 1998; Shaham et al, 2003).

*Correspondence: Dr P Popik, Institute of Pharmacology, Polish Academy of Sciences, 12 Smetna Street, 31-343 Kraków, Poland,

Tel: +48126623 375, Fax: + 481263745 00,

E-mail: nfpopik@cyf-kr.edu.pl

Received 20 December 2004; revised 28 March 2005; accepted 30 March 2005

Online publication: I April 2005 at http://www.acnp.org/citations/ Npp040 $105040593 /$ default.pdf
Rewarding stimuli, like drugs of abuse, evoke approach behavior in both humans and laboratory animals. When these stimuli become associated with initially neutral environment, exposure to such an environment can evoke approach behavior similar to the original rewarding stimulus (Pavlov, 1927). This observation is the basis of the conditioned place preference test (Carr et al, 1989), in which laboratory rodents associate the effects of a drug (unconditioned stimulus) with a distinctive arm of the test apparatus (conditioned stimulus). This drug-associated environment subsequently 'represents' subjective effects of the drug and produces an 'approach response.' Laboratory animals display conditioned place preference by spending more time in the drug-associated arm of the apparatus during the postconditioning test.

Conditioned responses produced through association of drug-effects with environmental cues represent a form of memory with long-lasting effects. Memory formation and processing are dynamic in that new memories are formed on the basis of reactivated old associations. Each time a memory trace is retrieved, it is reorganized, with new information being integrated into the existing memory (Spear and Mueller, 1984; Sara, 2000). Consequently, conditioned responses to drug-associated stimuli may be extinguished after exposure to these stimuli in a drug-free state (Numan et al, 1976; De Wit and Stewart, 1981). 
Throughout extinction, previously established responses are not eliminated but rather suppressed by newly formed associations (Pavlov, 1927; Rescorla, 2001). Once extinguished, drug-seeking behavior can be reinstated by the noncontingent injection of the drug (De Wit and Stewart, 1981) as well as localized enhancement of glutamatergic neurotransmission (Vorel et al, 2001).

Inhibitors of glutamatergic neurotransmission are effective in several models of drug dependence. In opioiddependent individuals, treatment with memantine, an $\mathrm{N}$-methyl-D-aspartate (NMDA) channel blocker (Parsons et al, 1999) attenuated the severity of opioid withdrawal syndrome and drug craving, and it increased the retention in treatment (Bisaga et al, 2001; Krupitsky et al, 2002). In laboratory animals, compounds that inhibit glutamatergic neurotransmission diminish the expression of conditioned place preference induced by morphine and cocaine (Popik and Danysz, 1997; Bisaga and Popik, 2000; Kotlinska and Biala, 2000; Suzuki et al, 2000; Popik et al, 2003). However, these effects are short-lived and their relevance to the study of relapse mechanisms is not clear.

Glutamate neurotransmission appears essential to brain plasticity including learning and memory processes (for a recent review see Riedel et al, 2003). While mesocorticolimbic dopamine systems are involved in opiate reward (Wise, 2004) including reinstatement phenomena (Shaham et al, 2003), these systems are under the control of glutamate afferents (Siggins et al, 2003; Sesack et al, 2003), expressing among others NMDA receptors (Gracy et al, 1997).

We aimed to model the clinical phenomenon of relapse by investigating reinstatement of conditioned place preference in laboratory mice. We hypothesized that treatment with memantine during extinction phase of morphine-conditioned place preference would block morphine-induced reinstatement of this response.

\section{METHODS}

\section{Subjects}

Male C57BL/6J/Han/IMP mice (Nofer Institute of Occupational Medicine, Lodz, Poland), 22-24 g of body weight were group-housed in the standard laboratory cages and kept in a temperature-controlled colony room $\left(21 \pm 2^{\circ} \mathrm{C}\right)$ with a 12 -h light/dark cycle (light on: 0700, off: 1900). Commercial food and tap water were available ad libitum. Each experimental group consisted of 8-10 mice per treatment. All mice were used only once.

\section{Apparatus}

The place preference apparatus consisted of three rectangular arms $\left(30 \times 15 \times 20 \mathrm{~cm}^{3}\right)$ spaced at $120^{\circ}$ from each other, which were all accessible from a triangular (central) platform (Popik et al, 2003). The apparatus was made of plastic and the three arms differed in distinctive visual, tactile, and olfactory cues. Thus, the white arm had a black floor with small holes in it and was marked with peppermint flavor, the one black arm with white rough floor was marked with anise flavor, and the other black arm with plain black floor had no flavor. One drop of the respective flavored oil (Humco, TX, USA) was placed at the end of an arm to prevent diffusion of odors into other arms. These distinct sensory cues served as conditioned stimuli. The guillotine doors, colored according to the respective wall colors, were inserted during conditioning sessions and were removed during the pre- and postconditioning tests. The ceiling of all three arms was transparent. During testing, location of the mouse was monitored through a closed circuit TV camera positioned directly above the apparatus. The apparatus had a dim indirect lighting ( $\sim 14$ Lux), comprising two $15 \mathrm{~W}$ bulbs positioned about $1 \mathrm{~m}$ above it. The floors were repeatedly washed and dried to keep the apparatus free of urine and feces.

\section{Procedure}

In general, experiments 1-5 were designed to first induce conditioned place preference (conditioning), second to extinguish it (extinction), and third to reinstate it with a challenge dose of morphine (priming) (see Figure 1). Testing was carried out in an experimental room supplied with white noise by an experimenter blind to the treatment conditions.

During the adaptation period, mice were carried into the testing room, where they were weighed and handled by moving them from one standard home cage to another in the proximity of the apparatus. This adaptation phase was intended to reduce the novelty and stress associated with handling, injections, and exposure to the apparatus. During the preconditioning test, mice were placed individually on the central triangular platform of the apparatus. Animals had free access to all three arms for $20 \mathrm{~min}$ and the time spent in each arm as well as the number of arm entries (a raw measure of locomotor activity) were recorded. The two arms registering similar preferences were identified and subsequently, one was paired with morphine (or its vehicle) and another with vehicle administration. The mean difference between times spent during the preconditioning test in the 'rewarded' and 'nonrewarded' arms of 21 groups

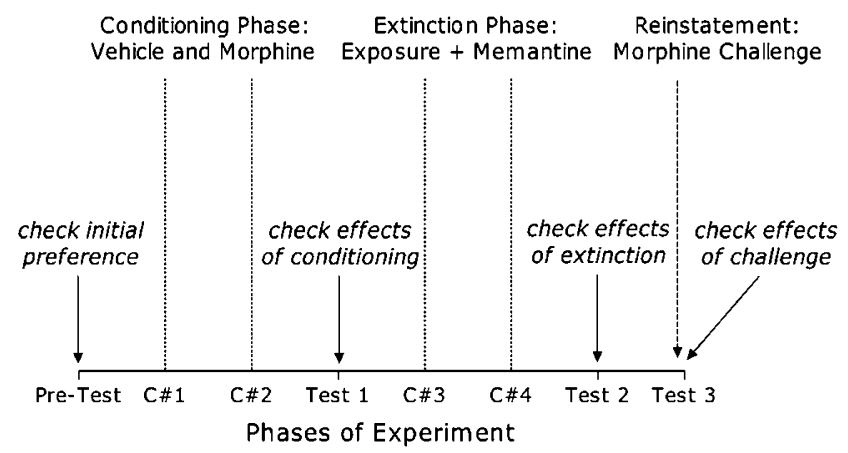

Figure I General design of experiments 1-5. All experiments were performed according to an unbiased procedure, and consisted of the following phases separated by $24 \mathrm{~h}$ : adaptation, preconditioning test, conditioning \# I with morphine, conditioning \#2 with vehicle (conditioning phase), and postconditioning test I. Next, conditionings \#3 and \#4 (extinction phase), followed by postconditioning test 2 were carried out. Finally, after 2 (Experiments 1-4) or 21 days (Experiment 5), postconditioning test 3 was performed preceded by the challenge with morphine or saline (reinstatement phase). 
tested was $30.2 \pm 2.4 \mathrm{~s}$. The unassigned arm could be either the most or least preferred of the three, and mice were not exposed to it during conditioning. This procedure was intended to reduce the initial imbalance of time spent in morphine vs vehicle-paired arms. Assignment of treatments to arms was evenly distributed and counterbalanced for mice in each group.

During conditionings \#1 and \#2, mice randomly assigned to treatment groups were treated with morphine $(10 \mathrm{mg} / \mathrm{kg})$ and vehicle (controls were treated with vehicle twice), immediately before being confined to the respective arm for $45 \mathrm{~min}$. The postconditioning test was similar to the preconditioning test. Animals had free access to all three arms for $20 \mathrm{~min}$ and the time spent in each arm was recorded. The above procedure was used to demonstrate the induction of conditioned place preference. Conditionings and test sessions were separated by $24 \mathrm{~h}$ and between testing mice were housed in their home cages.

\section{Design of Experiments}

Experiment 1: extinction of morphine-induced place preference and its reinstatement. For the next 2 days after test 1, morphine-conditioned mice and vehicle controls were treated with saline immediately before conditionings \#3 and \#4 and were placed in morphine- and vehicleassociated arms for $45 \mathrm{~min}$ of 'extinction' period. An additional morphine-conditioned group was similarly treated twice with saline, but exposed twice to the third (un-paired, ie, neutral) arm. All three groups were challenged with saline or morphine $(1 \mathrm{mg} / \mathrm{kg}) 20 \mathrm{~min}$ before postconditioning test 3 .

A separate experiment assessed if place preference conditioned with morphine could be inhibited by performing repeated postconditioning tests (eg, Parker and Mcdonald, 2000) instead of receiving separate exposures to morphine- and vehicle-associated arms. Since we failed to demonstrate extinction using this method for up to 7 days, these data are not shown here.

Experiment 2: specificity of reinstatement of extinguished morphine-induced place preference. Three groups of morphine-conditioned mice and two groups of vehicleconditioned mice were treated with saline before conditionings \#3 and \#4 and were placed in morphine- and vehicle-associated arms for $45 \mathrm{~min}$. An additional control morphine-conditioned group was treated during the extinction phase twice with morphine $(1 \mathrm{mg} / \mathrm{kg})$ instead of saline, and was similarly placed in morphine- and vehicleassociated arms. To evoke reinstatement, all these groups were challenged with saline or morphine (1 or $2.5 \mathrm{mg} / \mathrm{kg}$ ), $20 \mathrm{~min}$ before postconditioning test 3 .

Experiment 3: effects of treatment with memantine during extinction on morphine-induced reinstatement of extinguished place preference. Three morphine- and one vehicle-conditioned groups were treated with saline or memantine $(3.75$ or $7.5 \mathrm{mg} / \mathrm{kg}) 20 \mathrm{~min}$ before conditionings \#3 and \#4 and were placed in morphine- and vehicleassociated arms for $45 \mathrm{~min}$. These groups were challenged with saline or morphine $(1 \mathrm{mg} / \mathrm{kg}), 20 \mathrm{~min}$ before postconditioning test 3 .
Experiment 4: effects of various treatments during extinction on reinstatement of morphine-induced place preference. We tested a number of hypotheses that could explain the effects of memantine. To investigate if an anxiolytic compound would inhibit the reinstatement of morphine-conditioned place preference ('anxiolytic hypothesis'), a group of morphine-conditioned mice was treated with $10 \mathrm{mg} / \mathrm{kg}$ of chlordiazepoxide during the extinction phase and was challenged with morphine. To test the 'conditioned opioid withdrawal hypothesis' (see Discussion section), morphine-conditioned mice were extinguished with $1 \mathrm{mg} / \mathrm{kg}$ of morphine and were challenged with morphine. To investigate if a potent psychoactive compound purportedly changing perception would inhibit the reinstatement of morphine-induced place preference ('psychotomimetic hypothesis'), a group of morphineconditioned mice was treated with $0.5 \mathrm{mg} / \mathrm{kg}$ of LSD-25 (D-lysergic acid diethylamide) during the extinction phase and was challenged with morphine. Finally, we investigated if memantine would produce the same effects on extinction and reinstatement when given after (rather than $20 \mathrm{~min}$ before) extinction conditionings \#3 and \#4. Thus, immediately after conditionings and before returning to their home cages, mice received injections of $7.5 \mathrm{mg} / \mathrm{kg}$ of memantine.

Experiment 5: morphine-induced reinstatement of place preference response 21 days after extinction: effects of memantine. In parallel with Experiment 3, mice were treated with saline or memantine $(7.5 \mathrm{mg} / \mathrm{kg}) 20 \mathrm{~min}$ before conditionings \#3 and \#4. These animals were challenged with saline or morphine $(1 \mathrm{mg} / \mathrm{kg}), 21$ days after extinction conditionings, and 20 min before postconditioning test 3 .

Experiment 6: effect of memantine on learning. We also investigated the possibility that the main effect could be explained by memantine-induced impairment of learning. We choose the elevated plus maze because it allows investigation of cognitive as well as anxiolytic effects of treatment. In this particular test, unlike in other tests of memory (eg, food-reinforced T-maze or footshock-reinforced passive avoidance), mice use similar repertoire of sensory cues and behavioral output as in the place preference procedure. The elevated plus maze reliably assesses the memory of exploring a specific spatial location; the shorter latency to enter the 'safe' space on second exposure serves as the measure of intact cognitive functioning (Itoh et al, 1991).

The maze was made of black painted plywood and consisted of a central platform $\left(5 \times 5 \mathrm{~cm}^{2}\right)$ from which two open $\left(5 \times 30 \mathrm{~cm}^{2}\right)$ and two enclosed $\left(5 \times 30 \times 15 \mathrm{~cm}^{3}\right)$ arms extended (Lister, 1987). The apparatus was elevated to a height of $50 \mathrm{~cm}$ above the floor. The open arms were illuminated with two bright lamps $(\sim 1000$ Lux; the enclosed arms were kept dark $\sim 16$ Lux). In the first test, mice were individually placed at the end of one open arm facing away from the central platform. The latency of each mouse to find and enter (with four paws) one of the enclosed arms was measured (transfer latency 1 [TL\#1]) and mice were allowed to freely explore the apparatus for the following $10 \mathrm{~s}$. The second test was carried out $24 \mathrm{~h}$ later. As in the first test, mice were individually placed at the end of 
one open arm facing away from the central platform, and the latency to enter one of enclosed arms was measured (TL\#2). The apparatus was cleaned and dried after each animal. At 20 min before the first test mice were pretreated with saline, $7.5 \mathrm{mg} / \mathrm{kg}$ of memantine, or $0.1 \mathrm{mg} / \mathrm{kg}$ of MK801 (dizocilpine) used as a 'positive' control. This was designed to imitate drug treatment condition in the place preference procedure.

\section{Drugs}

Morphine $\mathrm{HCl}$ (Polfa, Krakow, Poland), memantine $\mathrm{HCl}$ (Tocris, UK, batch 4B/39049), MK-801 ((+)-5-methyl10,11-dihydroxy-5H-dibenzo(a,d)cyclohepten-5,10-imine maleate) (generous gift of Professor K Rice, NIDDK, NIH, Bethesda, MD, USA) and chlordiazepoxide (Polfa, Krakow, Poland) were dissolved in sterile physiological saline that served as vehicle. LSD-25 (D-lysergic acid diethylamide, Sandoz LTD, Basle, Switzerland) was used as the commercial solution. All solutions were made fresh the day of experiment. The doses of morphine are expressed as its base. All compounds were administered i.p. in the volume of $10 \mathrm{ml} / \mathrm{kg}$.

\section{Data Presentation and Statistics}

Data were summarized as the difference (Delta $[\mathrm{s}]$ ) between time spent in the morphine-associated arm during a postconditioning and the preconditioning test. The data were statistically evaluated using a two-way ANOVA (Statistica 5.0 for Windows) with the postconditioned test number as the within group factor and the treatment as the between groups factor. If the interaction between these factors was statistically significant $(P<0.05)$, data on a given postconditioned test were analyzed with separate oneway ANOVAs followed by post hoc Duncan's test. The same approach was used to analyze the number of arm entries recorded during the tests. However, with the exception of data presented on Figure $4 \mathrm{~b}$, these analyses did not reveal significant effects of conditionings on locomotor activity. Thus, these data are summarized as the minimal and maximal values, accompanied by corresponding two-way ANOVA results.

To assess whether control groups change their preferences for respective arms of the apparatus in the course of experiment, we carried out a series of two-way repeated measures ANOVAs with TEST NUMBER (pretest, test 1, 2, and 3 ) and ARM TYPE (A, B, and C; with arm A and B conditioned to the effects of vehicle and arm $\mathrm{C}$ being unpaired) as repeated-measure factors.

In Experiment 6, the decrease of entrance latency was summarized as the percent difference scores (TL\#1 $=100 \%$, $\mathrm{TL} \# 2=X \%)$ and analyzed using one-way ANOVAs and post hoc Duncan's test. Results were considered statistically significant at $P<0.05$.

\section{Ethics}

All experiments were carried out according to the National Institutes of Health Guide for Care and Use of Laboratory Animals (Publication No. 85-23, revised 1996), and this study was approved by the Institute of Pharmacology Animal Care and Use Bioethics Commission.

\section{RESULTS}

The validity of the experimental setup was estimated by assessing whether in control groups the distribution of time across all three arms remained stable over pre- and postconditioning tests. There were three independent vehicle-conditioned/saline-extinguished/saline-challenged groups (Groups VehVeh/SalSal/Sal; on Figures 2, 3,and 5). Three separate two-way repeated measures ANOVAs did not reveal significant interactions between test number and arm type: $\mathrm{F}(6,48)=0.80$, NS; $\mathrm{F}(6,42)=1.80, \mathrm{NS}$; $\mathrm{F}(6,48)=2.09$, NS, respectively. Thus, it appeared that control groups did not change their preferences for respective arms of the apparatus in the course of experiment.

In all groups conditioned to the effects of morphine, significant increase of time spent in the morphineassociated arm was observed on postconditioning test 1 (Groups MorVeh/Treatment,Treatment/Challenge in Figures 2, 3, 4a, 5, and 6).

\section{Experiment 1: Extinction of Morphine-Induced Place Preference and its Reinstatement (Figure 2)}

Extinction conditionings with the use of saline in the formerly morphine- and vehicle-associated arms produced subsequent reduction of conditioned preference on postconditioning test 2 (Group MorVeh/SalSal/Sal). However, extinction conditioning with the use of saline in the third (unpaired, ie, neutral) arm did not change place preference as assessed on postconditioning test 2 (Group MorVeh/ SalSal $_{\text {(neutral arm) }}$ /Mor).

Morphine-conditioned mice that were exposed to the whole apparatus every day for 7 days (repeated postconditioning tests) did not changed their preference for morphine-paired side (data not shown).

\section{Experiment 2: Specificity of Reinstatement of Extinguished Morphine-Induced Place Preference (Figure 3)}

As in Experiment 1, an extinction of conditioned preference was observed in the group MorVeh/SalSal/Sal. Extinction conditionings with the use of morphine (instead of saline) also produced extinction of conditioned place preference (group MorVeh/MorMor/Sal). The challenge with 1 and $2.5 \mathrm{mg} / \mathrm{kg}$ of morphine before postconditioning test 3 produced dose-dependent-like reinstatement of conditioned preference in morphine-conditioned, saline-extinguished

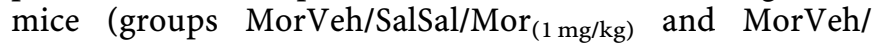
SalSal $\left./ \operatorname{Mor}_{(2.5 \mathrm{mg} / \mathrm{kg})}\right)$. However, morphine challenge produced no change in place preference in the vehicleconditioned, saline-extinguished group (VehVeh/SalSal/ $\left.\operatorname{Mor}_{(1 \mathrm{mg} / \mathrm{kg})}\right)$. 


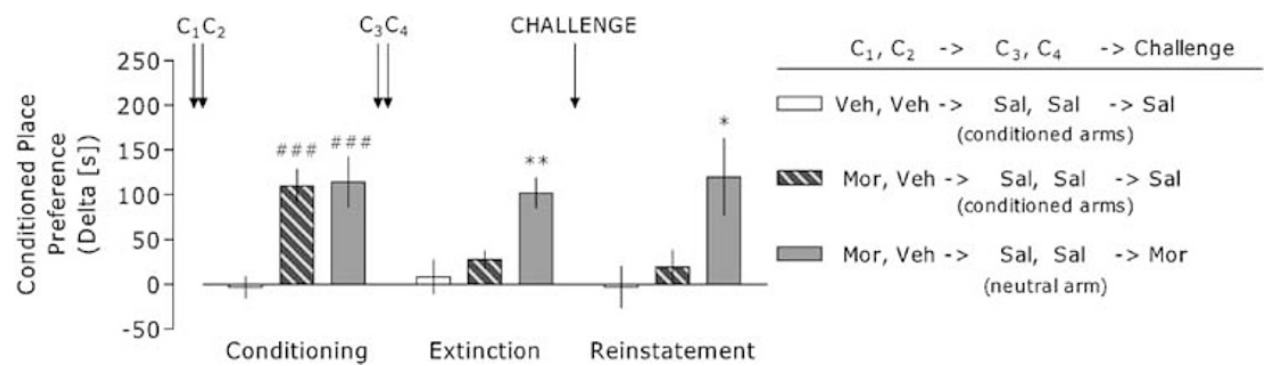

Figure 2 Extinction of morphine-induced place preference and its reinstatement. In Figures 2-6, the labels refer to the treatment used during conditioning/treatment during extinction/challenge before reinstatement. $\mathrm{N}$ in Figures 2-6: 8-10 mice per treatment. The rewarding effects of morphine (hatched and gray bars) were tested after conditioning during test I. During the extinction phase, mice were treated with saline and exposed to the previously morphine- and vehicle-associated arms of the apparatus (control group, represented as gray bars, was exposed to the unpaired, ie, neutral arm) Effects of this extinction procedure were assessed during test 2 . At 2 days after test 2 (and 20 min before test 3), mice received morphine or saline challenge. Two-way ANOVA demonstrated significant interaction between the treatment and test number: $F(4,48)=3.809$, $P<0.00$ I. Separate between-subject ANOVAs for tests I, 2, and 3 revealed significant effects of treatment: $F(2,24)=11.298,9.835$, and $4.978(P<0.00 I, P<0.00 I$, and $P<0.05)$, respectively. Post hoc Duncan's tests demonstrated significant effects of conditioning with morphine on test I (significance toward group 'vehicle-conditioned/extinguished with saline in the conditioned arms/saline-challenged'; $\# \# \#<0.001$ ), and the effects of extinction with saline (significance toward group 'morphineconditioned/extinguished with saline in the conditioned arms/saline-challenged'; $* P<0.05$, $* * P<0.01$ ). Two-way ANOVA on locomotor activity data (that ranged from $22.2 \pm 2.48$ entrances on test 3 in morphine-conditioned/saline-extinguished/saline-challenged to $31.75 \pm 2.31$ entrances on test I in morphineconditioned/saline-(in unpaired-arm)-extinguished/morphine challenged) revealed no significant effect of the interaction between the test number and treatment $F(4,48)=1.673$, NS.
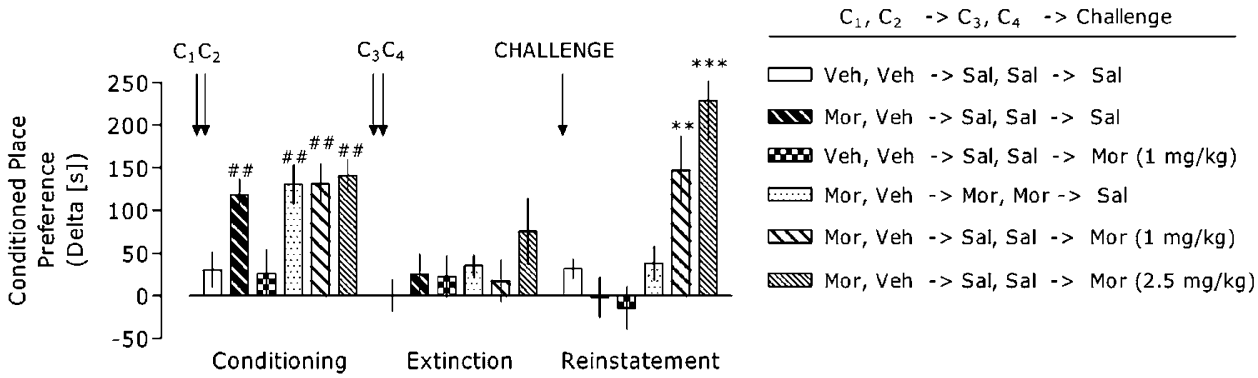

Figure 3 Specificity of reinstatement of extinguished morphine-induced place preference. During the extinction phase, morphine-conditioned mice were treated with saline (the control group represented by dotted bars was treated with morphine) and exposed to the previously morphine- and vehicleassociated arms of the apparatus. Test 2 revealed that all groups extinguished conditioned place preference. Before test 3 , mice were challenged with saline or morphine. Two-way ANOVA demonstrated significant interaction between treatment and test number: $F(I 0,96)=4.92$, $P<0.00 \mid$. Separate betweensubject ANOVAs for tests I, 2, and 3 revealed the following effects of treatment: $F(5,48)=5.44,0.99$ and $9.572(P<0.00 \mathrm{I}, \mathrm{NS}$ and $P<0.00 \mathrm{I})$, respectively Post hoc Duncan's tests demonstrated significant effects of conditioning with morphine on test I (significance toward group 'vehicle-conditioned/salineextinguished/saline-challenged', ${ }^{\# \#} P<0.0 I$ ), and the effects of a challenge with morphine before test 3 (significance toward group 'morphine-conditioned/ saline-extinguished/saline-challenged' $* * *<0.01$, **** $P<0.001$ ). Two-way ANOVA on locomotor activity data (that ranged from $21.25 \pm 2.79$ entrances on test $\mathrm{I}$ in vehicle-conditioned/saline-extinguished/morphine (I mg/kg)-challenged to $35.37 \pm 3.13$ entrances on test | in vehicle-conditioned/salineextinguished/saline-challenged) revealed no significant effect of the interaction between the test number and treatment $F(I 0,96)=0.998, N S$.

\section{Experiment 3: Effects of Treatment with Memantine during Extinction on Morphine-Induced Reinstatement of Extinguished Place Preference (Figure 4)}

In morphine-conditioned mice, extinction conditionings with the use of memantine produced reduction of place preference on postconditioning test 2 , similar to that observed in saline-extinguished animals. Compared with saline-treated animals, administration of memantine (7.5 but not $3.75 \mathrm{mg} / \mathrm{kg}$ ) blocked the ability of morphine challenge to reinstate the place preference on postconditioning test 3 (groups MorVeh/MemMem $(7.5 \mathrm{mg} / \mathrm{kg}) / \mathrm{Mor}$ and MorVeh/MemMem $(3.75 \mathrm{mg} / \mathrm{kg}) /$ Mor, respectively). In vehicleconditioned mice, extinction conditionings with the use of memantine did not affect preference on postconditioning test 2 (group VehVeh/MemMem $(7.5 \mathrm{mg} / \mathrm{kg} / \mathrm{Mor}$ ), and the morphine challenge preceding test 3 did not produce reinstatement (since this group was not initially conditioned to morphine).

\section{Experiment 4: Effects of Various Treatments during Extinction on Reinstatement of Morphine-Induced Place Preference (Figure 5)}

Investigation of 'anxiolytic hypothesis' revealed that extinction conditionings with the use of chlordiazepoxide $(10 \mathrm{mg} /$ $\mathrm{kg}$ ) produced reduction of place preference on postconditioning test 2; however, the challenge with morphine before postconditioning test 3 evoked reinstatement of conditioned preference in chlordiazepoxide-extinguished mice (Group MorVeh/CdpCdp/Mor). Investigation of 'opioid withdrawal hypothesis' revealed that extinction conditionings with the use of morphine $(1 \mathrm{mg} / \mathrm{kg})$ also produced a 

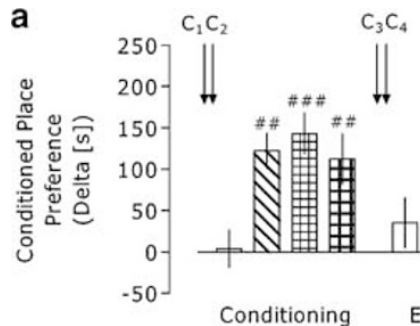<smiles>CC(C)(C)[13CH3]</smiles><smiles>C1CCC1</smiles>

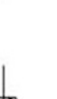

$$
\mathrm{C}_{1}, \mathrm{C}_{2} \rightarrow \mathrm{C}_{3}, \mathrm{C}_{4} \quad \rightarrow \text { Challenge }
$$

$\square$ Veh, veh $\rightarrow$ Mem, Mem (7.5) -> Mor alv Mor, Veh $\rightarrow$ Sal, Sal $\rightarrow$ Mor 曲回 Mor, Veh -> Mem, Mem (3.5) -> Mor WII Mor, Veh -> Mem, Mem (7.5) -> Mor Conditioning Extinction Reinstatement

b

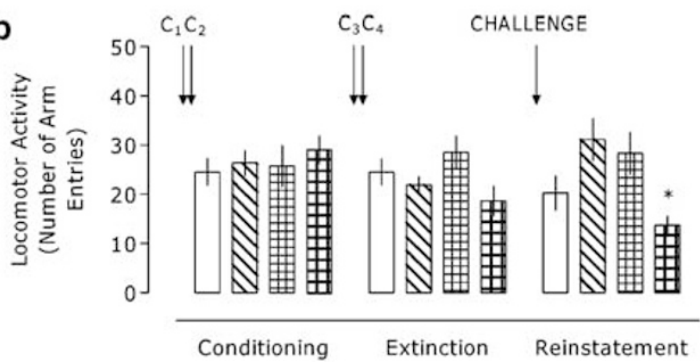

$\mathrm{C} 1_{1} \mathrm{C}_{2} \rightarrow \mathrm{C}_{3}, \mathrm{C}_{4} \quad \rightarrow$ Challenge

$\square$ Veh, Veh $\rightarrow$ Mem, Mem (7.5) -> Mor

NIV Mor, Veh $\rightarrow$ Sal, Sal $\quad \rightarrow$ Mor

표 Mor, Veh $>>$ Mem, Mem (3.5) $>>$ Mor

InI Mor, Veh $\rightarrow$ Mem, Mem (7.5) $\rightarrow$ Mor

Figure 4 Effects of treatment with memantine during extinction on morphine-induced reinstatement of extinguished place preference (a) and locomotor activity (b). During the extinction phase, morphine-conditioned groups and vehicle-conditioned control group were treated with saline or memantine and exposed to the arms as described in the legend to Figure 3. Test 2 revealed that all morphine-conditioned groups extinguished place preference response. Before test 3, mice were challenged with I mg/kg of morphine. (a) Two-way ANOVA demonstrated significant interaction between treatment and test number: $F(6,62)=5.079, P<0.00$ I. Separate between-subject ANOVAs for tests I, 2 , and 3 revealed the following effects of treatment: $F(3,31)=6.077$, 0.73 , and $5.638(P<0.0 \mathrm{I}, \mathrm{NS}$ and $P<0.0 \mathrm{I})$, respectively. Post hoc tests demonstrated significant effects of conditioning with morphine on test I (significance toward group 'vehicle-conditioned/extinguished with $7.5 \mathrm{mg} / \mathrm{kg}$ of memantine/morphine-challenged'; ${ }^{\# \#} P<0.0 \mathrm{I}$, \#\#\# $P<0.00 \mathrm{I}$ ), and effects of treatment with memantine $(7.5 \mathrm{mg} / \mathrm{kg}$ ) during extinction as evaluated during test 3 (significance toward group 'morphine-conditioned/saline-extinguished/morphinechallenged'; $* P<0.05$, *** $P<0.00$ I). (b) Two-way ANOVA on locomotor activity data (that ranged from I3.62 I I.87 entrances on test 3 in morphineconditioned $/ 7.5 \mathrm{mg} / \mathrm{kg}$ memantine-extinguished/morphine-challenged to $31.11 \pm 4.28$ entrances on test 3 in morphine-conditioned/saline-extinguished/ morphine-challenged) revealed significant effect of the interaction between the test number and treatment $F(6,62)=4$. I06, $P<0.01$. Separate betweensubject ANOVAs for locomotor activity data on tests I, 2, and 3 revealed the following effects of treatment: $F(3,31)=0.312,2.309$, and 4.354 (NS, NS and $P<0.05)$, respectively. Post hoc Duncan's tests demonstrated significant effects of treatment with memantine $7.5 \mathrm{mg} / \mathrm{kg}$ during extinction on locomotor activity of morphine-challenged mice revealed on test 3 (significance toward group 'morphine-conditioned/saline-extinguished/morphine-challenged'; $* P<0.05)$.

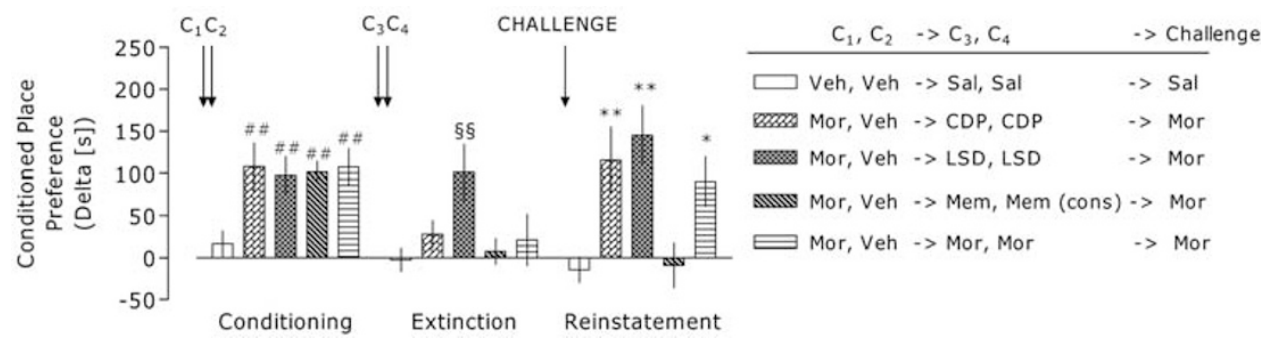

Figure 5 Effects of various treatments during extinction on reinstatement of morphine-induced place preference. Morphine-conditioned groups were treated with $0.5 \mathrm{mg} / \mathrm{kg}$ of LSD-25, $10 \mathrm{mg} / \mathrm{kg}$ of chlordiazepoxide, or I mg/ $/ \mathrm{kg}$ of morphine, $20 \mathrm{~min}$ before the extinction conditionings. Another morphineconditioned group was treated with $7.5 \mathrm{mg} / \mathrm{kg}$ of memantine immediately after the extinction conditionings. Vehicle-conditioned control group was treated with saline before the extinction phase. Before test 3, all morphine-conditioned groups were challenged with I mg/kg of morphine. Two-way ANOVA demonstrated significant effect of the interaction between treatment and test number: $F(8,92)=3.319, P<0.0$ I. Separate between-subject ANOVAs for tests I, 2 , and 3 revealed the following effects of treatment: $F(4,46)=3.515,3.17$, and $5.836(P<0.05, P<0.05$, and $P<0.00 I)$, respectively. Post hoc tests demonstrated significant effects of conditioning with morphine on test I ( ${ }^{\# \#} P<0.0$ I), extinction with LSD-25 on test $2\left({ }^{\S} P<0.0\right.$ I), and extinction with LSD, chlordiazepoxide and morphine on test 3 (*P<0.05; **P $<0.0$ I) (all significant effects toward the group 'vehicle-conditioned/saline-extinguished/salinechallenged'). Two-way ANOVA on locomotor activity data (that ranged from $20.21 \pm 2.29$ entrances on test 3 in morphine-conditioned/memantine-(given after conditionings)-extinguished/morphine-challenged to $29.0 \pm 2.24$ entrances on test 3 in morphine-conditioned/morphine-extinguished/morphinechallenged) revealed no significant effect of the interaction between the test number and treatment $F(8,92)=1.77 \mathrm{I}, \mathrm{NS}$.

decrease of place preference on test 2; and morphine challenge evoked a reinstatement of place preference (group MorVeh/MorMor/Mor). Investigation of 'psychotomimetic hypothesis' revealed that extinction conditionings with the use of LSD-25 $(0.5 \mathrm{mg} / \mathrm{kg})$ produced no change in place preference as revealed on test 2 (no extinction observed), and significant preference persisted after morphine challenge on test 3 (Group MorVeh/LsdLsd/Mor). Finally, investigation of 'consolidation hypothesis' demonstrated that treatment with memantine $7.5 \mathrm{mg} / \mathrm{kg}$ immediately after (rather than before) extinction conditionings produced reduction of place preference on postconditioning test 2 , 


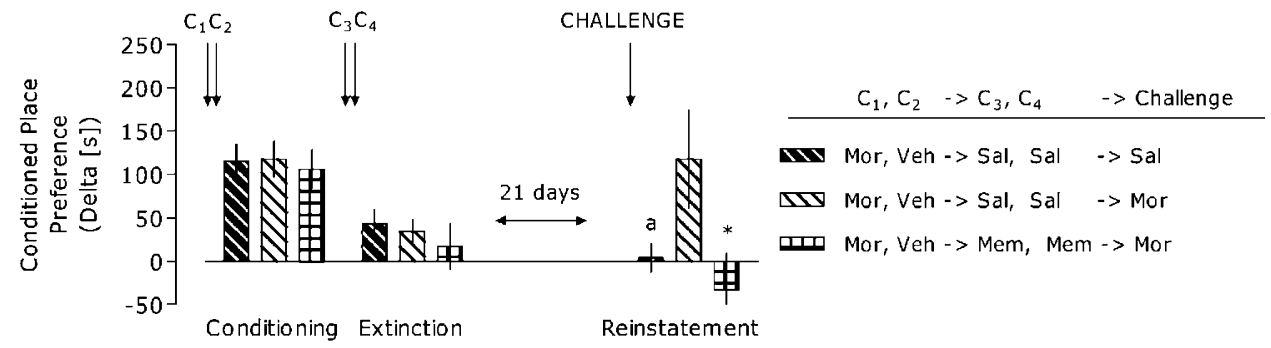

Figure 6 Morphine-induced reinstatement of place preference response 21 days after extinction: effects of memantine. During the extinction phase, morphine-conditioned groups were treated with saline or memantine and exposed to the arms as described in the legend of Figure 3 . Test 2 revealed that all morphine-conditioned groups extinguished place preference response. Just before test 3, carried out 21 days after extinction conditionings, mice were challenged with $1 \mathrm{mg} / \mathrm{kg}$ of morphine. Two-way ANOVA demonstrated significant effect of the interaction between the test number and treatment $F(4,46)=2.992, P<0.05$. Separate between-subject ANOVAs for tests I, 2 , and 3 revealed the following effects of treatment: $F(2,23)=0.08,0.46$ and 3.756 (NS, NS and $P<0.05$ ), respectively. Post hoc Duncan's tests demonstrated significant effects of treatment on test 3 (significance toward group 'morphineconditioned/saline-extinguished/morphine-challenged'; $* P<0.05$ ). In saline-extinguished mice, the difference between the effect of 'challenge' with saline and the challenge with morphine approached statistical significance ('a' $P=0.053$ ). Two-way ANOVA on locomotor activity data (that ranged from I4.5 \pm I.69 entrances on test 3 in morphine-conditioned/memantine-extinguished/morphine-challenged to $28.0+3.0$ entrances on test I in morphine-conditioned/ saline extinguished/morphine-challenged) revealed no significant effect of the interaction between the test number and treatment $F(4,46)=0.136, N S$.

Table I Effects of Memantine and MK-80I on Learning

\begin{tabular}{|c|c|c|c|c|}
\hline Treatment and dose (mg/kg) & $\mathbf{N}$ & TL\#I (s) & TL\#2 (s) & Difference (\%) \\
\hline Vehicle & 20 & $49.70 \pm 5.18$ & $13.20 \pm 1.59$ & $30.42 \pm 5.09$ \\
\hline Memantine 7.5 & 20 & $52.35 \pm 5.54$ & $16.20 \pm 2.37$ & $33.78 \pm 6.26$ \\
\hline MK-80I 0.1 & 24 & $60.08 \pm 4.96$ & $33.21 \pm 4.80 * * *$ & $63.28 \pm 9.92 * *$ \\
\hline ANOVA $F(2,61)=$ & & $1.12, \mathrm{NS}$ & $10.06, P<0.00 \mid$ & $5.66, P<0.01$ \\
\hline
\end{tabular}

Presented are mean \pm SEM latencies (s) to enter the enclosed arm of the apparatus during the first (transfer latency I (TL\#I)) and second (transfer latency 2 (TL\#2)) tests, respectively, as well as the mean difference between these times for each group (difference (\%) expressed as an average relative \% decrease between TL\# I ( I00\%) and TL\#2). Statistical analyses involved one-way ANOVAs performed on TL\#I, TL\#2 and difference (\%). Significant difference compared to vehicle treatment is indicated as $* * P<0.01$. MK-80I treatment resulted in the reduction of latency in test \#2 that was significantly less pronounced, suggesting a learning deficit.

but this treatment blocked the ability of morphine challenge to reinstate the place preference on postconditioning test 3 (group MorVeh/MemMem (cons) $/$ Mor).

\section{Experiment 5: Morphine-Induced Reinstatement of Place Preference Response 21 Days after Extinction: Effects of Memantine (Figure 6)}

The challenge with morphine before postconditioning test 3 produced reinstatement of place preference in saline, but not memantine $(7.5 \mathrm{mg} / \mathrm{kg})$ extinguished mice even 21 days after the extinction sessions. In saline extinguished mice, the effect of morphine challenge approached statistical significance $(P=0.053)$ compared to the 'challenge' with saline. However, memantine treatment during extinction phase clearly abolished the ability of morphine challenge to produce reinstatement (group MorVeh/MemMem/Mor).

\section{Experiment 6: Effects of Memantine on Learning (Table 1)}

Analyses of percent difference scores and TL \#2 (but not TL\#1 values) revealed significant differences among groups (Table 1). Although all treatments resulted in TL\#2 shorter than TL\#1, only mice treated with MK-801 demonstrated less pronounced shortening of transfer latencies on test \#2 compared to that of vehicle treatment.

\section{DISCUSSION}

In the present series of experiments, the model of morphine-conditioned place preference was used to study effects of an NMDA receptor antagonist on morphineprimed reinstatement of extinguished place preference. This preclinical paradigm models one of the central features of relapse in addictive disorders, namely the reinstatement of extinguished drug-conditioned response precipitated by the administration of the drug. The face and construct validity of preclinical models of relapse is supported by human studies (De Wit, 1996) and even though some of the clinical features of addictions (including the protracted nature of conditioning phenomena) are not reflected in animal models, these models can be used to study the neurobiology of relapse (Shalev et al, 2002).

In all morphine-conditioned groups, significant preference for the morphine-associated arm was observed on postconditioning test 1 . As in the study with rats (Mucha et al, 1982) single conditioning with morphine produced significant place preference. Administration of saline before exposure to the two conditioned (formerly morphine- and 
vehicle-associated) arms of the apparatus produced extinction of established place preference response. Exposure to the third (un-paired) arm of the apparatus in the drug-free state, repeated exposures to the whole apparatus (as done with performing everyday postconditioned tests; data not shown), as well as keeping conditioned animals in their home cages for 21 days (eg Popik et al, 1998) did not change the established place preference response. Extinction was also achieved by pairing morphine administration with exposure to both conditioned arms suggesting that the differential preference to the arm originally associated with morphine was lost because the vehicle-associated arm also became associated with effects of morphine.

The challenge with saline before the final test did not result in the reinstatement of extinguished response. However, challenge with morphine produced clear and dose-dependent reinstatement of place preference. Reinstatement was produced even when challenge with morphine was given 21 days following extinction. This relatively long-lasting persistence of drug-conditioned effect is consistent with clinical observations, indicating that drugconditioned responses persist for weeks or months in abstinent opioid abusers (O'Brien, 1975).

The challenge doses of morphine ( 1 and $2.5 \mathrm{mg} / \mathrm{kg}$ ) were chosen on the basis of our pilot experiments showing their ability to produce reinstatement (see also Wang et al (2000) for the use of low doses of morphine producing reinstatement). We explicitly attempted not to use the dose used during conditioning, as its effect would confound interpretation on the basis of the state-dependent phenomenon (conditioning and testing in the same state; Overton, 1974).

Interestingly, administration of morphine did not produce reinstatement in mice treated with the NMDA receptor antagonist, memantine ( 7.5 but not $3.75 \mathrm{mg} / \mathrm{kg}$ ) during the extinction phase. This inhibitory effect of memantine was observed even when mice were challenged with morphine 21 days later. However, treatment with memantine $(7.5 \mathrm{mg} /$ $\mathrm{kg}$ ) did not extinguish place preference response if the extinction conditionings were carried out in the unpaired arm, or in mice that were treated in their home cages rather than in conditioned arms of the apparatus (data not shown). A similar lack of effect of other NMDA receptor antagonists was previously reported (Popik et al, 1998), where the intact place preference response was observed in rats treated with the drugs in home cages. Altogether, these data are consistent with earlier observations indicating considerable persistence of established place conditioning (Mueller and Stewart, 2000; Manzanedo et al, 2001), and showing that the drug-related neuroadaptations are highly context-dependent (Siegel and Ramos, 2002). Our data support also recent findings indicating that systemic or intra-ventral tegmental area (VTA) administration of mGluR2/3 agonist inhibits cue-induced relapse to heroin seeking in rats (Bossert et al, 2004).

How could memantine treatment during extinction period 'protect' from the effects of morphine priming? Two processes operate simultaneously during saline-induced extinction. First, the original association is retrieved. Second, a novel association is formed between exposure to the previously drug-associated environment and the effects of saline administration. The novel association interacts with the original one in the process of re-consolidation
(Spear and Mueller, 1984; Sara, 2000). Recent data suggest that the associations that govern retrieval, reconsolidation, and coding of memories are highly dependent on glutamate transmission. Przybyslawski and Sara (1997) and Summers et al (1997) reported that NMDA receptor antagonists disrupted the performance of well-trained rats and chicks by affecting the reconsolidation of memories after their reactivation.

These mechanisms also apply to the drug-related associations. For instance, reinstatement of extinguished cocaine-seeking behavior can be induced by the electrical stimulation of the hippocampal glutamate/NMDA fibers, or via microinjection of NMDA into the VTA (Vorel et al, 2001). Therefore, one could expect that the inhibition of NMDA receptors might produce a reverse effect. Consistent with this idea, we have previously shown that administration of the NMDA receptor antagonist into VTA inhibits the expression of place preference conditioned with morphine (Popik and Kolasiewicz, 1999).

In the present experiments, memantine may have disrupted the processing of conditioned responses brought into the reactivated state during extinction. In mice extinguished with saline, chlordiazepoxide, or memantine during the extinction phase, the original association between the morphine-paired environment and the subjective effect of morphine becomes suppressed by a newly formed association (Schroeder and Packard, 2003), now signaling the subjective effect of 'no-morphine'. This was revealed by the absence of conditioned preference on test 2. The original preference could be reinstated by morphine challenge in animals extinguished with saline, chlordiazepoxide, or morphine. However, in memantineextinguished mice the original association between effects of morphine and the unique environment became so altered that the reinstating-effects of morphine challenge were blocked.

This effect of memantine could not be explained by blockade of the acquisition of a novel association. If memantine blocked learning, then mice would prefer the morphine-associated arm on test 2 as if never subjected to the extinction procedure. This is also supported by the results of Experiment 6, demonstrating that in a test specifically addressing cognitive abilities of mice, memantine failed to influence the learning processes. In contrast, MK-801, the compound with known amnestic properties, attenuated learning thus supporting the original observation in this experimental setting (Itoh et al, 1991). Therefore, we hypothesize that memantine might impair the re-consolidation of highly salient drug-related associations. This effect can be viewed as the opposite of the reinstatement produced by enhancement of NMDA/glutamate tone as described by Vorel et al (2001).

The alternative hypothesis is that memantine treatment during the extinction phase replaced or substituted for morphine association. Treatment with memantine could possibly have had an 'over-riding' effect on previous conditionings, so that morphine prime no longer produced the reinstatement. This hypothesis appears less likely, because at the dose used here, memantine itself produces neither place preference nor aversion (Popik and Danysz, 1997; Kotlinska and Biala, 2000). Second, during the extinction phase memantine administration was associated 
with the exposure to both formerly vehicle- and morphineassociated arms. This was done to prevent the 'novelty effect', that is, mice treated with a drug in one arm only could prefer it as a more interesting, due to purportedly weaker memory of 'being there'. However, the use of such a procedure also allows the exclusion of the 'overriding' hypothesis, because if memantine would 'over-ride' the previous associations, it would do so equally well to the vehicle- and drug-associations. As a result, the preference for morphine arm would be retained. This was not observed; instead, on test 2 no preference was noted. Lastly, during the extinction phase memantine was administered either before (Experiments 3 and 5) or after (Experiment 4) extinction conditionings. The effectiveness of treatment given after conditionings indicates that the process occurring after the association had happened was affected.

One could propose that memantine-treated mice were unable to recognize morphine-associated environment due to the fact that at higher doses, memantine, and other NMDA receptor antagonists, may produce psychotomimetic effects (Parsons et al, 1999). This explanation is unlikely due to several factors. First, memantine abolished the ability of morphine to produce reinstatement when given before, but also after extinction conditionings (Experiment 4). This suggests that memantine disrupted processing of the old and new associations, rather than impaired the extinction process per se. Disturbed perception would also affect learning processes, and this was not observed in the Experiment 6 . Additionally, mice treated with $0.5 \mathrm{mg} / \mathrm{kg}$ of the potent hallucinogenic drug, LSD-25, did not demonstrate extinction on test 2 , and continued to prefer the morphine-associated arm.

Bardo et al (1984) have demonstrated a relationship between levels of test session activity and expression of conditioned place preference. Specifically, morphine-conditioned rats given extinction training displayed more entries into the morphine-associated compartment, but did not display change in total duration spent in that environment. These findings raise the possibility that in our experiments, 'reinstating' injections of morphine could produce effects by altering activity levels during the test, rather than by reactivating a suppressed association. To test this hypothesis, the activity of mice during tests (the number of rewarded arm entries) was analyzed in a similar way as the time spent in that arm. Such analyses did not yield significant results in all experiments with the exception of Experiment 3 (Figure 4b). Interestingly, morphine-conditioned $/ 7.5 \mathrm{mg} / \mathrm{kg}$ memantine-extinguished/ morphine-challenged mice demonstrated less rewarded arm entries compared to similarly treated but saline-extinguished mice. Even though it may not be surprising that memantine-extinguished mice entered the rewarded arm less than saline-extinguished mice, it is unlikely that this effect explains the ability of memantine to block morphineproduced reinstatement. This is because we failed to observe changes in locomotor activity in other groups, particularly among mice extinguished with memantine given after conditionings (Figure 5) and memantineextinguished mice tested 21 days after conditionings (Figure 6). Our observations appear to agree with other findings that demonstrate the lack of a relationship between the test activity levels and expression of conditioned place preference (Shippenberg et al, 1989).

Finally, memantine might have suppressed symptoms of conditioned opiate-withdrawal that purportedly occurred in saline-treated (extinguished) mice placed in an environment previously associated with morphine's effects ('opioid withdrawal hypothesis'). Accordingly, in memantine-extinguished mice, cues related to morphine administration could no longer evoke conditioned withdrawal and could no longer contribute to the reinstatement of place preference. Indeed, in animal models, NMDA receptor antagonists block expression of opiate withdrawal (Bisaga and Popik, 2000) and produce anxiolytic-like effects. However, memantine shows no such effects in the Vogel conflict test or the elevated plus maze (Karcz-Kubicha et al, 1997, cf Parsons et al, 1999). It is unknown if a single dose of $10 \mathrm{mg} / \mathrm{kg}$ of morphine used for conditioning in mice could result in measurable withdrawal as reported by Krystal and Redmond (1983) in monkeys, but such possibility cannot be ruled out. This explanation appears less likely, as Experiment 4 demonstrated that in mice extinguished with chlordiazepoxide, a known anxiolytic and opiate withdrawal blocker (eg Bhargava, 1994), the morphine challenge produced reinstatement of conditioned response. Moreover, Experiment 4 also shows that in mice extinguished with morphine administration (that apparently would diminish purported withdrawal), morphine challenge was able to reinstate conditioned place preference.

In summary, the present findings indicate that treatment with the NMDA receptor antagonist memantine blocks the reinstatement of extinguished, morphine-conditioned responses. The 'protective' effect of brief treatment with memantine was also evident when mice were challenged with morphine 21 days after the conditioned response was extinguished. These findings suggest that memantine may also block the ability of drug-related cues to precipitate relapse in abstinent, opioid-dependent individuals. Moreover, the mechanisms mediating relapse in response to environmental cues are likely to be shared across other drugs of abuse, including alcohol (Shaham et al, 2003). An involvement of glutamatergic mechanisms in forms of neural plasticity and in chronic effects of several drugs of abuse would support this view (Bisaga and Popik, 2000). Therefore, findings reported here might have implications for treatment of other addictive disorders. Medication offering an extended protection against relapse may provide an important addition to psychosocial treatments. Such medication may be particularly useful in the relapseprevention phase of addiction treatment. Therefore, memantine, which is available for clinical use, may be useful in the treatment of drug dependence. Treatment trials should be conducted to establish the clinical efficacy of memantine.

\section{ACKNOWLEDGEMENTS}

This work was supported by the Polish State Committee for Scientific Research (Project PBZ 033/P05/2001). The authors thank Drs GF Koob, JH Krystal and T Shippenberg for stimulating and fruitful discussion, and B Adamcio for his excellent technical help. 


\section{REFERENCES}

Bardo MT, Miller JS, Neisewander JL (1984). Conditioned place preference with morphine: the effect of extinction training on the reinforcing CR. Pharmacol Biochem Behav 21: 545-549.

Bhargava HN (1994). Diversity of agents that modify opioid tolerance, physical dependence, abstinence syndrome, and selfadministrative behavior. Pharmacol Rev 46: 293-324.

Bisaga A, Comer SD, Ward A, Popik P, Kleber HD, Fischman MW (2001). The NMDA antagonist memantine attenuates the expression of opioid physical dependence in humans. Psychopharmacology 157: 1-10.

Bisaga A, Popik P (2000). In search of a new pharmacological treatment of drug addiction: $N$-methyl-D-aspartate (NMDA) antagonists. Drug Alcohol Depend 59: 1-15.

Bossert JM, Liu SY, Lu L, Shaham Y (2004). A role of ventral tegmental area glutamate in contextual cue-induced relapse to heroin seeking. J Neurosci 24: 10726-10730.

Carr GF, Fibiger HC, Phillips AG (1989). Conditioned place preference as a measure of drug reward. In: Liebman J, Cooper SJ (eds). The Neuropharmacological Basis of Reward. Clarendon Press: Oxford. pp 264-319.

De Wit H (1996). Priming effects with drugs and other reinforcers. Exp Clin Psychopharm 4: 5-10.

De Wit H, Stewart J (1981). Reinstatement of cocaine-reinforced responding in the rat. Psychopharmacology (Berl) 75: 134-143.

el Guebaly N, Hodgins D (1998). Substance-related cravings and relapses: clinical implications. Can J Psychiatry 43: 29-36.

Gracy KN, Svingos AL, Pickel VM (1997). Dual ultrastructural localization of mu-opioid receptors and NMDA-type glutamate receptors in the shell of the rat nucleus accumbens. J Neurosci 17: 4839-4848.

Itoh J, Nabeshima T, Kameyama T (1991). Utility of an elevated plus-maze for dissociation of amnesic and behavioral effects of drugs in mice. Eur J Pharmacol 194: 71-76.

Kotlinska J, Biala G (2000). Memantine and ACPC affect conditioned place preference in rats. Pol J Pharmacol 52: 179-185.

Krupitsky EM, Masalov DV, Burakov AM, Didenko TY, Romanova TN, Bespalov AY et al (2002). A pilot study of memantine effects on protracted withdrawal (syndrome of anhedonia) in heroin addicts. Addict Disord Treat 1: 143-146.

Krystal JH, Redmond Jr DE (1983). A preliminary description of acute physical dependence on morphine in the vervet monkey. Pharmacol Biochem Behav 18: 289-291.

Leshner AI (1997). Addiction is a brain disease, and it matters. Science 278: 45-47.

Lister RG (1987). The use of a plus maze to measure anxiety in the mouse. Psychopharmacology 92: 180-185.

Manzanedo C, Aguilar MA, Rodriguezarias M, Minarro J (2001). Conditioned place preference paradigm can be a mouse model of relapse to opiates. Neurosci Res Commun 28: 23-29.

McLellan AT, Lewis DC, O'Brien CP, Kleber HD (2000). Drug dependence, a chronic medical illness: implications for treatment, insurance, and outcomes evaluation. JAMA 284: 1689-1695.

Mucha RF, Van der Kooy D, O'Shaughnessy M, Bucenieks P (1982). Drug reinforcement studied by the use of place conditioning in the rat. Brain Res 243: 91-105.

Mueller D, Stewart J (2000). Cocaine-induced conditioned place preference: reinstatement by priming injections of cocaine after extinction. Behav Brain Res 115: 39-47.

Numan R, Banerjee U, Smith N, Lal H (1976). Secondary reinforcement property of a stimulus paired with morphine administration in the rat. Pharmacol Biochem Behav 5: 395-399.

O'Brien CP (1975). Experimental analysis of conditioning factors in human narcotic addiction. Pharmacol Rev 27: 533-543.
O’Brien CP, Childress AR, Ehrman R, Robbins SJ (1998). Conditioning factors in drug abuse: can they explain compulsion? J Psychopharmacol 12: 15-22.

Overton DA (1974). Experimental methods for the study of statedependent learning. Fed Proc 33: 1800-1813.

Parker LA, Mcdonald RV (2000). Reinstatement of both a conditioned place preference and a conditioned place aversion with drug primes. Pharmacol Biochem Behav 66: 559-561.

Parsons CG, Danysz W, Quack G (1999). Memantine is a clinically well tolerated $N$-methyl-D-aspartate (NMDA) receptor antagonist- a review of preclinical data. Neuropharmacology 38: 735-767.

Pavlov IP (1927). Conditioned Reflexes. Oxford University Press: London.

Popik P, Danysz W (1997). Inhibition of reinforcing effects of morphine and motivational aspects of naloxone-precipitated opioid withdrawal by NMDA receptor antagonist, memantine. J Pharmacol Exp Ther 280: 854-865.

Popik P, Kolasiewicz W (1999). Mesolimbic NMDA receptors are implicated in the expression of conditioned morphine reward. Naunyn-Schmied Arch Pharmacol 359: 288-294.

Popik P, Kozela E, Wrobel M, Wozniak KM, Slusher BS (2003). Morphine tolerance and reward but not expression of morphine dependence are inhibited by the selective glutamate carboxypeptidase II (GCP II, NAALADase) inhibitor, 2-PMPA. Neuropsychopharmacology 28: 457-467.

Popik P, Mamczarz J, Fraczek M, Widla M, Hesselink M, Danysz W (1998). Inhibition of reinforcing effects of morphine and naloxone-precipitated opioid withdrawal by novel glycine site and uncompetitive NMDA receptor antagonists. Neuropharmacology 37: 1033-1042.

Przybyslawski J, Sara SJ (1997). Reconsolidation of memory after its reactivation. Behav Brain Res 84: 241-246.

Rescorla RA (2001). Experimental extinction. In: Mowrer RR, Klein S (eds). Handbook of Contemporary Learning Theories. Erlbaum: Mahwah, NJ. pp 119-154.

Riedel G, Platt B, Micheau J (2003). Glutamate receptor function in learning and memory. Behav Brain Res 140: 1-47.

Sara SJ (2000). Retrieval and reconsolidation: toward a neurobiology of remembering. Learn Mem 7: 73-84.

Schroeder JP, Packard MG (2003). Systemic or intra-amygdala injections of glucose facilitate memory consolidation for extinction of drug-induced conditioned reward. Eur J Neurosci 17: $1482-1488$.

Sesack SR, Carr DB, Omelchenko N, Pinto A (2003). Anatomical substrates for glutamate-dopamine interactions: evidence for specificity of connections and extrasynaptic actions. Ann NY Acad Sci 1003: 36-52.

Shaham Y, Shalev U, Lu L, De Wit H, Stewart J (2003). The reinstatement model of drug relapse: history, methodology and major findings. Psychopharmacology (Berl) 168: 3-20.

Shalev U, Grimm JW, Shaham Y (2002). Neurobiology of relapse to heroin and cocaine seeking: a review. Pharmacol Rev 54: 1-42.

Shippenberg TS, Emmett-Oglesby MW, Herz A (1989). Morphineinduced place conditioning is not confounded by drug-induced alterations in locomotor activity. Pharmacol Biochem Behav 32: 129-132.

Siegel S, Ramos BM (2002). Applying laboratory research: drug anticipation and the treatment of drug addiction. Exp Clin Psychopharmacol 10: 162-183.

Siggins GR, Martin G, Roberto M, Nie Z, Madamba S, De Lecea L (2003). Glutamatergic transmission in opiate and alcohol dependence. In: Moghaddam B, Wolf ME (eds). Ann NY Acad Sci. The New York Academy of Sciences: New York, NY. pp 196-211.

Spear NE, Mueller CW (1984). Consolidation as a function of retrieval. In: Weingartner H, Parker ES (eds). Memory Consolidation: Psychobiology of Cognition. Lawrence Erlbaum Associates: Hillsdale, NJ. pp 111-147. 
Summers MJ, Crowe SF, Ng KT (1997). Administration of DL-2amino-5-phosphonovaleric acid (AP5) induces transient inhibition of reminder-activated memory retrieval in day-old chicks. Cognitive Brain Res 5: 311-321.

Suzuki T, Kato H, Aoki T, Tsuda M, Narita M, Misawa M (2000). Effects of the non-competitive NMDA receptor antagonist ketamine on morphine-induced place preference in mice. Life Sci 67: 383-389.

Vorel SR, Liu X, Hayes RJ, Spector JA, Gardner EL (2001). Relapse to cocaine-seeking after hippocampal theta burst stimulation. Science 292: 1175-1178.

Wang B, Luo F, Zhang WT, Han JS (2000). Stress or drug priming induces reinstatement of extinguished conditioned place preference. NeuroReport 11: 2781-2784.

Wise RA (2004). Dopamine, learning and motivation. Nat Rev Neurosci 5: 483-494. 